\title{
KELAYAKAN FINANSIAL UNIT PENGOLAHAN KARET DENGAN CREPER MINI (STUDI KASUS DI DESA PULAU HARAPAN, KABUPATEN BANYUASIN)
}

\author{
Financial Feasibility of Rubber Processing Factory with Mini Creper \\ (Case Study in Pulau Harapan Village, Banyuasin District)
}

\author{
Aprizal Alamsyah, Iman Satra Nugraha, Dwi Shinta Agustina, dan Lina Fatayati Syarifa \\ Balai Penelitian Sembawa - Pusat Penelitian Karet \\ Jln. Raya Palembang - Betung KM 29, PO. BOX 1127 ,Palembang 30001 \\ Email: aprizal_alamsyah@yahoo.co.id
}

Diterima 5 Januari 2016 / Direvisi 6 September 2016 / Disetujui 15 Desember 2016

\begin{abstract}
Abstrak
Rendahnya mutu bokar yang dihasilkan petani menjadi problema klasik hingga saat ini. Biasanya petani karet mengolah lateks hasil kebun yang dicetak dalam bak pembeku dan berbentuk slab dengan berbagai ukuran. Harga yang diterima petani rendah, karena lemahnya posisi tawar seharusnya dapat ditingkatkan apabila membuat bokar bersih. Upaya peningkatan mutu bokar dapat dilakukan dengan adanya unit pengolahan karet creper mini sekaligus peluang berinvestasi bagi petani - pedagang. Creper mini digunakan untuk mengolah bokar atau slab tipis menjadi blanket yang diharapkan akan meningkatkan harga ditingkat petani. Tulisan ini merupakan ulasan studi kasus pada unit pabrik pengolahan karet creper mini di Kabupaten Banyuasin, Sumatera Selatan. Kajian dilakukan untuk mengetahui kelayakan finansial kegiatan usaha pengolahan karet dengan creper mini. Indikator kelayakan finansial yang digunakan adalah NPV, B/C ratio, IRR dan PBP. Hasil analisis menunjukkan NPV Rp. 1.225.200.360,- B/C Ratio1,02, IRR 32\% dan PBP 25 bulan. Hal tersebut menunjukkan usaha pengolahan karet dengan creper mini dinilai layak. Namun, berdasarkan analisis sensitivitas ketika harga karet rendah menggunakan skenario penurunan harga jual dan harga beli bahan baku blanket sebesar 30\% dan 33\%, maka nilai NPV Rp 673.100.520,- B/C Ratio1,02, IRR18\% dan PBP 41 bulan. Kondisi tersebut
\end{abstract}

menguntungkan namun peka terhadap gejolak ekonomi dikarenakan nilai IRR sama dengan DF $18 \%$.

Kata kunci: kelayakan finansial, creper mini, blanket

\section{Abstract}

The low quality of raw rubber materials produced by farmers is a classic problem up this time. Usually, farmers were done of latex processing by printed in the freezer tub and shaped "slab" in various sizes. Farmers had received relatively low prices, because the weak bargaining position that would otherwise be beneficial to make a clean "bokar". The efforts for improvement of raw material could be conducted by the presence of rubber processing unit creper mini both an opportunity to invest for the farmer- traders. Creper mini hadused to process the raw material rubber into blankets which expected to beable to increase farmers' income. This article is a reviews of case studies in factory unit creper mini on in Banyuasin district, South Sumatera. The study analyzeswere conducted to the financial aspects with financial eligibility criterias such as NPV, B/C Ratio,IRR and $P P$. The results of analyzed were $N P V R p$. 1.225.200.360,-, B/C Ratio 1,02, IRR 32\%, and PBP 25 months. Business continuity rubber processing units with mini creper is feasible. However, based on sensitivity analysis when using low rubber prices scenario decrease in selling prices and raw material blanket purchase price by $30 \%$ 
and $33 \%$, the NPV Rp. 673.100.520,- B/C Ratio 1,02, IRR $18 \%$ and PBP 41 months. The condition is favorable, but sensitive to economic shocks due to the value of IRR is equal to DF $18 \%$.

\section{Keywords: financial feasibility, mini creper, blankets}

\section{Pendahuluan}

Perbaikan mutu bokar di tingkat petani dapat dilakukan melalui penerapan creper mini (Suwardin, 1988 dan Suwardin et al., 1989) serta penggunaan koagulan yang direkomendasikan (Praharnata et al., 2016).Penggunaan creper mini di Banyuasin telah dimanfaatkan petani untuk tidak menjual bokar dalam bentuk bekuan sleb melainkan membuat blanket. Penerapan teknologi pengolahan bokar dengan creper mini mampu memberikan nilai tambah, penghematan biaya pengolahan $30 \%$ dan meningkatkan pendapatan petani karet 10\% (Suwardin dan Nancy, 1990 dan Syahja, 2010). Unit pengolahan creper mini terdiri dari gilingan (mangel) yang digerakkan dengan mesin diesel berkekuatan $60 \mathrm{Hp}$ dilengkapi dengan unit pompa air. Fungsi utama mesin creper adalah pembersihan (pemisahan kotoran) dan mengurangi ketebalan dengan penggesekan (shearing) koagulum (bekuan karet berupa slab), serta mempercepat proses pengeringan. Kinerja mesin creper dipengaruhi oleh tipe dan ukuran rol, kecepatan dan nisbah friksi, serta pola/bentuk alur rol yang digunakan. Efek kerja gilingan creper selain untuk pembersihan dan penyempurnaan blending juga memperbaiki struktur koagulum (mengurangi kadar air) sehingga mempercepat pengeringan (Suwardin, 1995). Tujuan utama penggilingan remahan adalah untuk mendapatkan keseragaman bahan baku dengan proses mikro dan menjadikannya dalam bentuk lembaran (Suprapto, 2012).

Hasil olahan mesin creper mini adalah blanket (lembaran karet basah hasil gilingan) dengan ketebalan 0,6 cm -1,0 cm dan KKK 65\% - 75\% (Amypalupy, 2010). Pengolahan slab berdasarkan SNI BOKAR adalah dengan menggiling slab tipis menggunakan gilingan tangan (hand mangel) sehingga diperoleh blanket. Keuntungan membuat slab tipis menjadi blanket adalah: (1) Mutu seragam, bersih dan KKK tinggi; (2) Pengangkutan dan pengolahan di pabrik lebih efisien; (3) Nilai PRI tinggi; (4) Dapat dijual langsung ke industri barang jadi karet (Solichin et al., 2003; 2012).

Keberadaan unit pabrik pengolahan blanket dengan mesin creper mini telah berlangsung sejak awal tahun 1990-an (Suwardin et al., 1990). Namun, penerapan mesin creper mini di tingkat petani karet dan pedagang masih menghadapi berbagai kendala yang membatasi berkembangnya penerapan teknologi ini (Supriadi et al., 1992). Kendala utama adalah modal usaha yang relatif besar. Petani karet sering mengalami kesulitan dalam memenuhi persyaratan untuk mendapatkan pinjaman modal.

Menurut Negara (2011), terdapat beberapa jenis usaha di sektor ekonomi yang kesulitan memperoleh kredit perbankan, tingkat suku bunga komersial yang tinggi telah menjadi hambatan serius bagi industri manufaktur, dan sebagian besar bank menganggap ini tidak lagi menguntungkan sehingga akses untuk mendapatkan skema kredit bank tidak mudah. Kesulitan memperoleh kredit memberikan kontribusi terhadap rendahnya investasi usaha.

Perkembangan teknologi terapan pengolahan karet alam dengan menggunakan mesin creper mini dianggap masih sangat relevan. Meskipun demikian, perlu dilakukan analisis kelayakan suatu usaha untuk meyakinkan pihak perbankan. Kadariah dalam Rahayu et al. (2006) menyatakan maksud analisis kelayakan usaha adalah untuk memperbaiki pemilihan investasi. Penentuan suatu usaha sebaiknya dilakukan setelah memperoleh hasil perhitungan kelayakan agardapat mengatasi resiko selama kegiatan usaha dan tidak mengalami kerugian.

Keberadaan pabrik pengolahan bokar menggunakan creper mini membantu meningkatkan mutu karet alam dan menambah pendapatan petani dengan kualifikasi harga berdasarkan mutu karet (blanket) yang dihasilkan (Suwardin dan Rosmija, 1989). Pengolahan blanket dengan 
creper mini secara berkelompok memiliki potensi untuk dapat dikembangkan, meningkatkan pendapatan petani, efisiensi energi dan mengurangi limbah (Zen et al., 1999).

Tujuan penelitian ini untuk menganalisis kelayakan finansial penggunaan mesin creper mini pada skala usaha unit pabrik pengolahan karet di Desa Pulau Harapan, sehingga dapat diketahui nilai tambah yang dihasilkan oleh pelaku usaha, sekaligus mengungkap kendala dan tantangan yang dihadapi. Selain itu, untuk mengetahui kondisi finansial usaha pada saat terjadi penurunan harga jual yang disebabkan oleh adanya penurunan harga karet.

\section{Metode Analisis}

Penelitian studi kasus mengenai creper mini ini dilaksanakan untuk memberikan gambaran mengenai kelangsungan usaha secara finansial pabrik pengolahan blanket yang berada di wilayah sentra perkebunan karet rakyat. Kegiatan dilaksanakan pada tahun 2013. Lokasi usaha berada di wilayah sentra perkebunan karet rakyat tepatnya Desa Pulau Harapan, Kabupaten Banyuasin. Pabrik pengolahan karet dengan creper mini ini dipilih sebagai lokasi penelitian dan masih beroperasi secara berkelanjutan setelah sempat tidak beroperasi dalam kurun waktu tertentu dikarenakan keterbatasan modal. Pengambilan data primer dilakukan melalui wawancara mendalam dengan pemilik usaha creper mini, sedangkan data sekunder diperoleh dari jurnal, laporan, dan penelitian-penelitian terdahulu.

Menurut Gittinger (1986); Kadariah (1999) analisis kelayakan investasi menggunakan beberapa metode sebagai indikator kelayakan proyek, antara lain:

1. Nilai Sekarang / NPV (Net Present Value).

$$
N V P=\sum_{t=n}^{n} \frac{B t-C t}{(1-i)^{t}}
$$

Keterangan:

Bt : Jumlah penerimaan kotor dari usaha pada tahun $\mathrm{t}$

Ct : Jumlah pengeluaran kotor dari usaha pada tahun $t$

n : Umur ekonomis

i : Bunga potongan(Discount rate)

$\mathrm{NPV}>0$ : Investasi yang dilakukan memberikan keuntungan, sehingga usaha layak

$\mathrm{NPV}<0 \quad$ : Investasi yang dilakukan memberikan kerugian, sehingga usaha tidak layak

2. Rasio Manfaat dan Biaya atau Benefit / Cost Ratio Analysis (B/C Ratio).

$\frac{B}{C}$ Ratio $=\frac{\sum_{t=n}^{n} \frac{(B t-C t)}{\left(1+i_{2}\right)^{t}}}{\sum_{t=n}^{n} \frac{(C t-B t)}{\left(1+i_{1}\right)^{t}}}$

Keterangan:

Bt : Benefit kotor pada tahun ke-t

Ct : Biaya kotor pada tahun ke-t

$\mathrm{n}$ : Umur ekonomis perusahan/proyek

i : Bunga potongan (discount rate)

$(1+\mathrm{i})$ : Discount factor (Df)

B/C Ratio > 1 : Usaha tersebut layak dilaksanakan

$\mathrm{B} / \mathrm{C}$ Ratio $=1$ : Usaha tersebut mengembalikan modal persis sama

B/C Ratio < 1: Usaha tersebut tidak layak

3. Tingkat Suku Bunga Pengembalian Modal atau Internal Rate of Return (IRR).

$I R R=i_{1}+\frac{\left(N P V_{1}\right)}{\left(N P V_{1}-N P V_{2}\right)}\left(i_{1}-i_{2}\right)$

Keterangan:

$\mathrm{NPV}_{1}$ : NPV pada tingkat discount rate tertinggi

$\mathrm{NPV}_{2}$ : NPV pada tingkat discount rate terendah

$\mathrm{i}_{1} \quad$ : Discount rate $\mathrm{NPV}_{1}$

$\mathrm{i}_{2} \quad$ : Discountrate $\mathrm{NPV}_{2}$

IRR $\geq$ Cost of capital maka proyek dianggap layak

IRR $\leq$ Cost of capital maka proyek dianggap tidak layak 
4. Periode Pengembalian Modal (Payback Period Analysis).

Kriteria penilaiannya adalah semakin singkat pengembalian investasi akan semakin baik. Metode ini mencoba mengukur seberapa cepat investasi bisa kembali (Nurmalina et al., 2009). Usaha ini dikatakan layak jika nilai PP kurang dari umur bisnis atau $\mathrm{PP}<$ umur usaha.

5. Analisis sensitivitas dilakukan untuk meneliti kembali analisis kelayakan proyek yang telah dilakukan, tujuannya yaitu untuk melihat pengaruh yang akan terjadi apabila keadaan berubah.

Hal ini merupakan suatu cara untuk menarik perhatian pada masalah utama proyek yaitu proyek selalu menghadapi ketidakpastian yang dapat terjadi pada suatu keadaan yang telah diramalkan.

Asumsi-asumsi yang digunakan dalam menganalisis kelayakan unit pabrik pengolahan karet dengan creper mini, yaitu:

- Produksi karet tetap dalam kurun waktu berjalan selama 10 tahun.

- Permintaan blanket tetap selama 10 tahun.

- Pabrik pengolahan blanket yang menggunakan mesin creper mini, meliputi biaya total, biaya investasi, biaya pengolahan dan biaya-biaya pemasarannya.

- Tanah tidak diperhitungkan sebagai biaya investasi dikarenakan hak milik/tidak sewa.

- Pembayaran ke petani oleh unit pengolahan creper mini dalam bentuk blanket, yaitu Rp12.000,-/kg merupakan harga yang terjadi sepanjang bulan Agustus sampai dengan September 2013.
- Harga produk berupa blanket yang terjadi pada bulan September 2013 Rp 14.300,$/ \mathrm{kg}$.

- Blanket mengalami susut $4 \%$ dari total produksi.

- Discount Factor 18\%.

- Penyusutan peralatan dihitung dengan menggunakan metode garis lurus dengan nilai sisa nol (0).

- Umur ekonomis mesin 10 tahun.

- Analisis sensitivitas menggunakan skenario penurunan harga jual blanket dan harga beli bahan baku blanket sebesar 30\% dan $33 \%$ secara simultan.

\section{Hasil dan Pembahasan}

\section{Gambaran umum usaha creper mini}

Keberadaan unit pengolahan blanket dengan menggunakan creper mini di Banyuasin telah ada sejak lama terdapat 9 (sembilan) pabrik pengolahan blanket dengan creper mini. Masing-masing berada di desa Mainan (3 lokasi),Limau (1 lokasi), Langkan (3 lokasi), Tanjung Menang Darat (1 lokasi), dan Pulau Harapan (1 lokasi). Pabrik pengolahan blanket di desa Pulau Harapan sebagai lokasi yang dipilih, telah beroperasi mulai tahun 1990. Namun, sempat berhenti beroperasi di tahun 1999 karena kesulitan pembiayaan modal usaha, akan tetapi kembali beroperasi di tahun 2004 sampai sekarang. Sumber bahan baku untuk memenuhi kapasitas produksi pabrik ini diperoleh dari petani karet di beberapa desa yang berada di Banyuasin dan Musi Banyuasin. Saat ini jumlah petani yang rutin menjual sleb ke pabrik creper mini di Pulau Harapan mencapai 300 orang per minggu.

Petani rata-rata membawa sleb dengan berat $60-100 \mathrm{~kg}$ untuk digiling di pabrik pengolahan dengan menggunakan creper mini

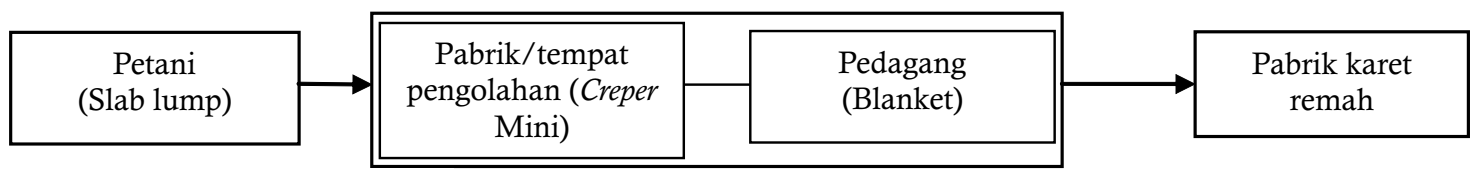

Sumber: Data primer

Gambar 1. Rantai pemasaran blanket oleh petani-pedagang 
(Gambar 2). Proses penggilingan dilakukan oleh tenaga operator unit mesin creper mini sehingga sleb menjadi blanket. Blanket hasil penggilingan ditimbang dan dibeli oleh pemilik usaha creper mini. Blanket dipasarkan langsung ke pabrik crumb rubber di Palembang berdasarkan ketentuan harga yang disepakati.

\section{Kapasitas produksi mesin creper mini}

Creper mini dengan 3 mesin memiliki kapasitas terpasang 1.920 ton/tahun. Satu mesin beroperasi selama 8 jam per hari yang menghasilkan blanket $275 \mathrm{~kg} / \mathrm{jam}$ sehingga menghasilkan 2,2 ton blanket/hari. Sementara untuk kapasitas riil creper mini dalam waktu operasi satu jam mampu membuat $138 \mathrm{~kg}$ blanket sehingga dalam 1 hari kerja satu mesin mampu menghasilkan 1,1 ton blanket. Dengan demikian, kemampuan creper mini dengan menggunakan 3 mesin hanya mencapai 960 ton pertahun. Data perbandingan kapasitas terpasang dan kapasitas riil unit pabrik pengolahan karet dengan menggunakan mesin creper mini dapat dilihat pada Tabel 1 .

Pada Tabel 1 terlihat bahwa kapasitas riil yang digunakan pelaku usaha baru mencapai $50 \%$ kapasitas terpasang, sehingga keuntungan belum tercapai secara optimal dikarenakan ketersediaan bahan baku dan modal yang masih terbatas.

Tabel 1. Perbandingan kapasitas terpasang dan kapasitas riil mesin creper mini

\begin{tabular}{ll}
\hline \multicolumn{1}{c}{ Kapasitas terpasang } & \multicolumn{1}{c}{ Kapasitas riil } \\
\hline Produksi $=40$ ton $/$ minggu $=160$ ton $/$ bulan & Produksi $=20$ ton $/$ minggu $=80$ ton $/$ bulan \\
$=1.920$ ton $/$ tahun $(3$ mesin $)$ & $=960$ ton $/$ tahun $(3$ mesin $)$ \\
1 mesin $=13,3$ ton blanket $/$ minggu & 1 mesin $=6,7$ ton blanket $/$ minggu \\
1 hari $=8$ jam $=2,2$ ton blanket & 1 hari $=8$ jam kerja $=1,1$ ton blanket \\
1 jam $=275 \mathrm{~kg}$ blanket & 1 jam $=138 \mathrm{~kg}$ blanket \\
\hline
\end{tabular}

Sumber: Data primer diolah(2013)

\section{Analisis biaya}

- Biaya investasi unit creper mini

Biaya investasi dikeluarkan pada saat awal usaha yaitu tahun ke-0. Biaya ini merupakan biaya dalam pengadaan barang-barang investasi, yaitu: biaya pengadaan mesin dan bangunan. Besaran biaya investasi yang dikeluarkan oleh pabrik pengolahan bokar dengan creper mini pada investasi awal yaitu sebesar Rp 790.000.000,00 yang meliputi biaya mangel (gilingan), mesin penggerak dan bangsal/gudang. Mesin creper mini yang dipakai mampu membuat 40 ton blanket per minggu atau 1,9 juta kg blanket dalam satu tahun, sehingga dibutuhkan biaya investasi awal yang besar. Rincian biaya pabrik pengolahan creper mini dapat dilihat pada Tabel 2.

Penyusutan masing-masing barang investasi dipengaruhi umur teknis dari barang investasi. Dasar penentuan umur teknis diperoleh dari lama barang tersebut dapat dipergunakan dengan layak. Barang-barang investasi seperti mangel (gilingan), mesin penggerak, dan pompa air serta bangunan gudang diasumsikan mengalami penyusutan

Tabel 2. Rincian biaya investasi unit creper mini tahun 2013

\begin{tabular}{lcrr}
\hline \multicolumn{1}{c}{ Komponen } & $\begin{array}{c}\text { Jumlah } \\
\text { (unit) }\end{array}$ & Harga/unit (Rp) & \multicolumn{1}{c}{ Nilai (Rp) } \\
\hline Mangel (gilingan) & 3 & $200,000,000$ & $600,000,000$ \\
Mesin penggerak & 3 & $45,000,000$ & $135,000,000$ \\
Pompa air & 2 & $5,000,000$ & $10,000,000$ \\
Bangsal Pengolahan dan Gudang & 1 & $45,000,000$ & $45,000,000$ \\
\hline TOTAL & & & $790,000,000$ \\
\hline Kapas
\end{tabular}

Kapasitas riil : 20 ton/minggu

Sumber: Data primer 
dengan proporsi yang sama (10\%) setiap tahunnya selama umur ekonomis 10 tahun, dan tidak memiliki nilai sisa.Tanah tempat berdirinya pabrik pengolahan blanket dengan creper mini tidak diperhitungkan umur ekonomisnya karena tanah dapat dipergunakan sepanjang tahun (melebihi umur usaha) dan tidak berkurang nilainya.

- Biaya operasional pengolahan blanket dengan crepermini

Biaya operasional adalah biaya yang dikeluarkan selama berlangsungnya usaha pabrik pengolahan bokar/pembuatan blanket dengan mesin creper mini. Biaya operasional terdiri dari beban biaya pengolahan dan biaya pemasaran. Beban biaya pengolahan terdapat beberapa komponen antara lain upah giling, minyak solar, pelumas, pemeliharaan mesin dan bangunan, penyusutan alat dan bangunan, serta upah jaga gudang. Pada kegiatan pemasaran telah dihitung biaya per kilogram blanket yang dihasilkan mesin creper mini seperti biaya angkutan, susut angkut, bongkar muat, administrasi, keamanan, pajak bokar (PPh 0,5\%) dan lain-lain.
Biaya operasional yang dikeluarkan untuk mengolah blanket adalah sebesar $\mathrm{Rp}$. $1.265,00 / \mathrm{kg}$ dengan rata-rata produksi pertahun mencapai 960 ton blanket. Rincian biaya pengolahan dan biaya pemasaran yang dikeluarkan tiap kilogram blanket yang diperoleh dapat dilihat pada Tabel 3 .

\section{Neraca laba rugi pengolahan blanket}

Dalam analisis laba rugi usaha, laba operasi diperoleh dari selisih penerimaan dan total biaya. Penerimaan diperhitungkan dari hasil penjualan blanket ke pabrik setelah dikurangi susut bobot sebesar $4 \%$ dalam 1 minggu. Selanjutnya biaya diperhitungkan dari biaya tetap (penyusutan dan pemeliharaan aktiva) dan biaya variabel (upah, bahan baku, bahan bakar, pelumas, biaya pemasaran dan pajak). Analisis laba rugi usaha pengolahan bokar dengan mesin creper mini dapat dilihat pada Tabel 4.

\section{Kelayakan investasi}

Usaha pengolahan blanket menggunakan creper mini diasumsikan berjalan selama 10

Tabel 3. Biaya operasional usaha creper mini

\begin{tabular}{lc}
\hline \multicolumn{1}{c}{ Komponen } & Biaya (Rp/kg blanket) \\
\hline Biaya pengolahan & 200 \\
- Upah giling & 33 \\
- Minyak solar & 11 \\
- Minyak pelumas & 31 \\
- Pemeliharaan mesin & 2 \\
- Pemeliharaan bangunan & 86 \\
- Biaya penyusutan alat dan bangunan & 30 \\
- Upah jaga gudang & \\
\hline Total biaya pengolahan & \\
\hline Biaya pemasaran & 75 \\
- Angkutan & 572 \\
- Susut angkut & 31 \\
- Bongkar muat & 16 \\
- Administrasi & 7 \\
- Keamanan & 72 \\
- Pajak & 100 \\
- Lain-lain & 872 \\
\hline Total biaya pemasaran & \\
\hline TOTAL & 1.265 \\
\hline
\end{tabular}

Sumber: Data primer diolah (2013) 
Tabel 4. Neraca laba rugi usaha pengolahan bokar dengan mesin creper mini

\begin{tabular}{lcccr}
\hline \multicolumn{1}{c}{ Penerimaan } & Satuan & $\begin{array}{c}\text { Jumlah } \\
(\mathrm{kg})\end{array}$ & $\begin{array}{c}\text { Harga/ } \\
\text { satuan }(\mathrm{Rp})\end{array}$ & \multicolumn{1}{c}{ Nilai (Rp) } \\
\hline Penjualan blanket & kgblanket & 921.600 & 14.300 & $13,178,880,000$ \\
Total penerimaan & & & $13,178,880,000$ \\
& & & \\
Biaya tetap & & & $158,000,000$ \\
Penyusutan alat & & & $31,680,000$ \\
Pemeliharaan aktiva & & & \\
Biaya variabel & & & $220,800,000$ \\
Upah giling dan jaga & & & 12.000 \\
Bahan baku & kg blanket & 960.000 & & $42,000,000$ \\
Minyak solar, pelumas & & & \\
Biaya pemasaran & & & $68,000,000$ \\
Pajak bokar (0,5\%) & & & $12,809,360,000$ \\
Total biaya (FC+VC) & & & $369,520,000$ \\
Laba operasi & & & \\
\hline
\end{tabular}

Sumber: Data primer diolah (2013)

tahun. Dengan harga blanket yang berlaku Rp $14.300,00$ pada tiap bulan berjalan, maka pendapatan bersih dari penjualan blanket baru akan diperoleh diawal tahun ketiga sebesar $\mathrm{Rp}$ 273.148.680,00. Kelayakan finansial unit pengolahan karet dengan menggunakan crepermini ini dapat dilihat dari beberapa kriteria penilaian investasi yaitu Net Present Value (NPV), Net B/C Ratio, Payback Period (PBP), dan Internal Rate of Return (IRR). Hasil perhitungan kriteria penilaian investasi pada usaha pengembangan pabrik pengolahan karet dengan creper mini dapat dilihat pada Tabel 5 .

Hasil analisis kelayakan, dapat dilihat bahwa usaha unit pengolahan karet dengan creper mini menghasilkan NPV yang lebih besar dari nol, yaitu sebesar Rp 1.225.200.360,00. Berdasarkan kriteria NPV unit pengolahan karet dengan creper mini ini dianggap layak untuk diusahakan. Nilai Net
B/C Ratio yang diperoleh yaitu sebesar 1,02. Hal ini berarti setiap Rp 1,00 yang dikeluarkan dalam usaha ini, maka akan menghasilkan manfaat sebesar Rp 1,02. Nilai Net B/C Ratio yang diperoleh lebih dari satu, sehingga usaha ini dinilai layak untuk dijalankan. Nilai IRR yang diperoleh yaitu sebesar 32 persen dimana IRR tersebut lebih dari discount factor (df) yang ditetapkan yaitu 18 persen. Dengan demikian, berdasarkan kriteria IRR usaha unit pengolahan karet dengan creper mini ini layak untuk dikembangkan. Payback Period (PBP) dapat diperoleh setelah usaha berjalan selama dua puluh lima bulan. Nilai PBP ini masih berada dibawah umur proyek, sehingga berdasarkan kriteria PBP usaha ini layak untuk dikembangkan. Seluruh aspek finansial yang dibahas pada pengembangan kelangsungan usaha unit pengolahan karet dengan creper mini dinyatakan layak karena seluruh kriteria

Tabel 5. Kriteria kelayakan investasi usaha pengolahan karet dengan creper mini

\begin{tabular}{lr}
\hline Kriteria kelayakan investasi & Nilai \\
\hline Net Present Value (NPV) & 1.225 .200 .360 \\
Net B/C Ratio & 1,02 \\
IRR (\%) & 32 \\
Payback Period(bulan) & 25 \\
Titik Impas (ton) & 1,916 \\
\hline
\end{tabular}

Sumber: Data primer diolah (2013) 
telah memenuhi syarat. Keberlanjutan usaha unit pabrik pengolahan karet dengan creper mini masih sangat layak dan memberikan peluang usaha bagi petani-pedagang.

\section{Analisis sensitivitas}

Analisis sensitivitas sangat perlu dilakukan pada setiap kegiatan usaha yang akan berjalan maupun sedang berjalan. Dengan analisis ini pelaku usaha/bisnis dapat melihat kondisi usaha/bisnis tersebut masih dalam kondisi layak atau tidak jika terjadi gejolak ekonomi sehingga pelaku bisnis dapat melakukan tindakan atau antisipasi untuk mempertahankan usaha/bisnis tersebut. Pada usaha pabrik pengolahan karet dengan creper mini perlu dilakukan antisipasi jika terjadi penurunan harga karet. Pada analisis ini menggunakan skenario jika terjadi penurunan harga karet sehingga secara simultan terjadi penurunan harga jual blanket dan pembelian bahan baku blanket sebesar 30\% dan 33\%. Hasil analisis sensitivitas tersebut dapat dilihat pada Tabel 6.

Berdasarkan Tabel 6, dapat dilihat bahwa jika terjadi penurunan harga karet sehingga mengakibatkan turunnya harga jual blanket dan bahan baku blanket sebesar 30\% dan 33\% akan mempengaruhi kegiatan usaha/bisnis ini. Hal tersebut dapat dilihat dari nilai NPV sebesar Rp. 673.100.520,00. Kondisi tersebut sudah mendekati titik impas, sedangkan nilai IRR sudah sama dengan nilai df yang digunakan sehingga usaha ini sangat sensitif terhadap perubahan harga. Syarat suatu proyek nilai IRR harus lebih besar dari df. Pengembalian investasi juga mengalami penambahan waktu dari 21 bulan menjadi 41 bulan.

\section{Kendala, dan tantangan usahapabrik pengolahan karet dengan creper mini}

Dalam pelaksanaannya unit pengolahan karet dengan menggunakan creper mini masih memiliki kendala, antara lain: minimnya modal usaha untuk pembelian bahan baku dan tidak stabilnya pasokan bahan baku sehingga produksi dari mesin creper mini tidak bisa dijalankan secara optimal. Minimnya modal usaha sangat menentukan keberlangsungan usaha pabrik pengolahan karet. Upaya petani untuk mendapatkan pinjaman modal tidak mudah, terdapat prasyarat wajib yang berlaku untuk dapat mengakses dana pinjaman perbankan, dan berkaitan dengan kemampuan petani untuk membayar angsurannya. Pendapatan yang diterima petani bukan hanya untuk operasional kegiatan usaha akan tetapi juga untuk memenuhi kebutuhan sehari-hari.

Keterlibatan petani dalam pemasaran bersama tentu akan memberikan nilai tambah, dan tentunya kualitas bokar yang dipasarkan dapat bermutu baik (Alamsyah et al., 2006). Di beberapa wilayah perkebunan karet rakyat, peran kelembagaan memberikan peluang usaha bagi kelangsungan pemasaran bokar dengan persyaratan mutu yang baik (Nancy et al., 2012; Syarifa, 2013), namun model pengolahan blanket dengan memanfaatkan eksistensi kelembagaan petani karet belum dapat dilaksanakan. Nancy et al. (1992) mengungkapkan keikutsertaan petani dalam pembuatan sleb giling seringkali tidak didasarkan pertimbangan ekonomi saja, namun karena adanya keterikatan dengan pedagang sebagai pengelola gilingan tangan. Pasokan bokar dalam jumlah besar berkelanjutan tentu menjadi faktor pendukung. Karena itu, kegiatan pengolahan

Tabel 6. Analisis sensitivitas pada saat harga jual blanket dan bahan baku blanket turun menjadi $30 \%$ dan $33 \%$

\begin{tabular}{lr}
\hline Kriteria kelayakan investasi & Nilai \\
\hline Net Present Value (NPV) & 673.100 .520 \\
Net B/C Ratio & 1,02 \\
IRR (\%) & 18 \\
Payback Period (bulan) & 41 \\
Titik Impas (ton) & 2.640 \\
\hline
\end{tabular}


dalam pemasaran bokar perlu pengorganisasian lebih lanjut.

Di sisi lain, pelaku usaha menyadari pentingnya menjaga ketersediaan bahan baku untuk memenuhi kapasitas produksi mesin serta tetap menjaga mutu bokar melalui pemilihan bahan baku yang bersih (Saputra et al., 2015) sehingga produk-produk yang dihasilkan memiliki keunggulan komparatif dan kompetitif dari negara pesaing (Malian dan Djauhari, 1999 dan Sabriwan, 2012). Strategi yang dilakukan adalah dengan menjaga hubungan baik dengan petani pelanggan dan mengupayakan kerjasama yang saling menguntungkan dengan kelompok ataupun gapoktan karet. Namun demikian, adanya persaingan harga untuk mendapatkan bahan baku karet milik petani tidak bisa dihindari.

\section{Kesimpulan}

Pengembangan usaha pabrik pengolahan bokar menjadi blanket dengan mesin creper mini dinyatakan layak untuk dijalankan setelah dilakukan perhitungan beberapa kriteria kelayakan, yang ditunjukkan oleh nilai NPV sebesar Rp 1.225.200.360,-, IRR 32\% dan Payback Period 25 bulan. Sedangkan berdasarkan analisis sensitivitas jika terjadi penurunan harga jual blanket dan harga beli bahan baku blanket sebesar 30\% dan 33\% akan menghasilkan nilai NPV Rp 673.100.520, IRR 18\% dan Payback Periode 41 bulan. Strategi untuk mendapatkan bahan baku agar kapasitas produksi optimal dapat dicapai melalui kerjasama dengan kelompok tani karet dan menjalin hubungan mitra dengan kelembagaan pemasaran bersama di setiap desa. Selain itu juga peran pemerintah sangat diharapkan untuk dapat memberikan kesempatan bagi pelaku usaha untuk mengembangkan usaha ini dengan bantuan modal yang melibatkan kerjasama pihak perbankan. Berkembangnya usaha pabrik pengolahan karet dengan creper mini dapat meningkatkan mutu bokar, harga yang diterima di tingkat petani, dan merangsang tumbuhnya sentra-sentra ekonomi lainnya di wilayah pedesaan, seperti keberadaan pasar dan pusat pertokoan.

\section{Daftar Pustaka}

Alamsyah, Z., Napitupulu, D., Elwamendri, dan Suprayitno. (2006). Analisis Pemasaran Bokar "Suatu Kajian Terhadap Upaya Peningkatan Kesejahteraan Petani Karet Melalui Pembenahan Tataniaga Bokar" di Provinsi Jambi. Diakses dari http : //www.ecampus.fkip.unja.ac.id.

Amypalupy, K. (2010). Teknik Okulasi. 455 Info padu padan teknologi merajut asa ketangguhan agribisnis karet (pp.86-96). Balai Penelitian Sembawa : Pusat Penelitian Karet.

Gittinger, J.P. (1986). Analisa ekonomi proyekproyek pertanian. Cetakan kedua. Jakarta : Universitas Indonesia Press.

Kadariah. (1999). Pengantar evaluasi proyek. Jakarta : Lembaga Penerbit Fakultas Ekonomi Universitas Indonesia.

Malian, H., dan Djauhari, A. (1999). Upaya Perbaikan Kualitas Bahan Olah Karet Rakyat. Forum Penelitian Agro Ekonomi, 17(2), 43-50.

Nancy, C., Suwardin, D., dan Supriadi, M. (1992). Kajian penerapan unit pengolahan gilingan tangan: Kasus di desa Durian Daun dan Mulia Agung Kabupaten Musi Banyuasin, Sumatera Selatan. Buletin Perkebunan Rakyat, 8(2), 56-68.

Negara, S.D. (2011). Determinants of fragmentation in manufacturing industries: a Case study of the electronics and textile industries in Indonesia. Review of Indonesian economic and business studies. Economic Research Center Vol 2 no 1 (23-49). Jakarta : Lembaga Ilmu Pengetahuan Indonesia.

Nurmalina R., Sarianti, T., dan Karyadi, A. (2009). Studi Kelayakan Bisnis. Bogor : Departemen Agribisnis Fakultas Ekonomi dan Manajemen Institut Pertanian Bogor. Butt Design and Printing.

Praharnata, Sulistyo, J., dan Wijayanti, H. (2016). Pengaruh Penggunaan Nanas dan Umbi Pohon Gadung Sebagai Koagulan Terhadap Kualitas Bahan Olah Karet Rakyat. Jurnal Konversi, 5(1). 27-34. 
Rahayu, P.S., Nastiti, D., dan Nurbani. (2006). Analisis finansial usaha tani pola tata air mikro di Kecamatan AngganaKabupaten Kutai Kertanegara. Widyariset, 9, 221-227.

Sabriwan, A. (2012, Desember 4). Pengolahan Bahan Olah Karet Rakyat. Diakses dari http://tambang-estate.blogspot.co.id /2012/12/pengolahan-bahan-olahankaret-rakyat.html.

Saputra, N. E., Yamin, M., Putri, N.E. (2015). Persepsi Pihak Pabrik Pengolahan Karet Terhadap Kualitas Sleb Rakyat dan Persepsi Petani Karet Terhadap Standar Sleb Pabrik Pegolahan Karet PT. Aneka Bumi Pratama. Jurnal Komunikasi Agribisnis, 3(2), 296-312.

Solichin, M., Suwardin, D., dan Vachlepi, A. (2012). Pengolahan. Saptabina Usahatani Karet Rakyat (pp.105-118) Edisi khusus cetakan keenam. Sembawa : Balai Penelitian Sembawa - Pusat Penelitian Karet.

Solichin, M., Suwardin, D., Raswil, R., Santoso, A., dan Anwar, A. (2003). Pengolahan bahan olah karet rakyat. Saptabina Usahatani Karet Rakyat. Sembawa Balai Penelitian Sembawa- Pusat Penelitian Karet.

Suprapto, B.Y. (2012). Prototipe monitoring pengeringan blanket karet menggunakan Supervisory Control and Data Acquisition (SCADA). Prosiding Seminar Nasional SciEtec, Malang, Februari 2012.

Supriadi, M., Nancy, C., dan Suwardin, D.(1992). Keragaan kelompok tani pengolahan karet di Desa Pulau, Musi Banyuasin, Sumatera Selatan. Buletin Perkebunan Rakyat. 8(1), 8-16.

Suwardin, D. (1995). Peningkatan mutu bokar dan pendapatan petani melalui penerapan mesin creper mini. Warta Pusat Penelitian Karet, 14(2), 102-109.
Suwardin, D., dan Nancy, C. (1990). Kajian penerapan creper mini di tingkat petani : Studi kasus di desa Pulau, Musi Banyuasin, Sumatera Selatan. Prosiding Konferensi Nasional Karet, Palembang, September 1990.

Suwardin, D., Anwar, C., Tamini, R., Nababan, K., dan Aman, A. (1990). Tinjauan sistem bapak angkat dalam meningkatkan mutu Bokar dan Pendapatan Petani di Sumatera Selatan. Prosiding Konferensi Nasional Karet, Palembang, September 1990.

Suwardin, D., Arifin, M. S., dan Anwar, C. (1989). Mesin creper mini untuk pengolah bahan olah karet rakyat di tingkat petani. Proceeding Rubber Growers Conference, Kuala Lumpur, 2007.

Suwardin, D., dan Rosmija. (1989). Uji coba mesin giling tipe creper mini: Pengaruh lama penyimpanan sleb dan jumlah giling terhadap mutu blanket. Buletin Perkebunan Rakyat, 5(1), 16-20.

Suwardin, D. (1988). Perbaikan mutu bahan olah karet rakyat melalui sistem bapak angkat. Lateks, 3(1), 33-36.

Syahja, A., Backe, D., dan Hamlin, N. (2015). Strategi Percepatan Pembangunan Ekonomi Melalui Penataan Kelembagaan dan Industri Karet Alam di Provinsi Riau. Diakses dari http://almasdi.staff.unri.ac.id /files / 2015 /08/02_Makala-BKSBarat_Palangkaraya-2015-Karet.pdf

Syarifa, L. F. (2013). Laporan Akhir Penelitian TA 2013 Buku II Penguatan dan penumbuhan kelompok pemasaran bokar terorganisir di Provinsi Sumatera Selatan. Balai Penelitian Sembawa : Pusat Penelitian Karet.

Zen, Z., Newman, P., and Stocker, L. (1999). Moving toward sustainability in agroforestry: The case of smallholder rubber in Indonesia. Journal of Policy Studies, 7. 